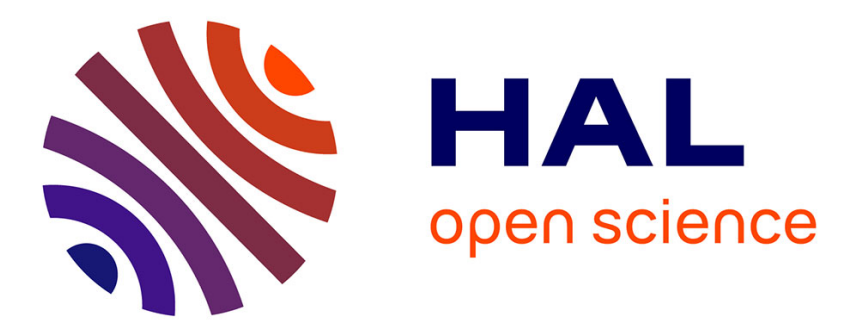

\title{
Changes in atmospheric sulfur burdens and concentrations and resulting radiative forcings under IPCC SRES emission scenarios for 1990-2100
}

\author{
Maï Pham, Olivier Boucher, Didier Hauglustaine
}

\section{- To cite this version:}

Maï Pham, Olivier Boucher, Didier Hauglustaine. Changes in atmospheric sulfur burdens and concentrations and resulting radiative forcings under IPCC SRES emission scenarios for 1990-2100. Journal of Geophysical Research: Atmospheres, 2005, 110 (D6), pp.D06112. 10.1029/2004JD005125 . hal00069270

\author{
HAL Id: hal-00069270 \\ https://hal.science/hal-00069270
}

Submitted on 20 Feb 2016

HAL is a multi-disciplinary open access archive for the deposit and dissemination of scientific research documents, whether they are published or not. The documents may come from teaching and research institutions in France or abroad, or from public or private research centers.
L'archive ouverte pluridisciplinaire HAL, est destinée au dépôt et à la diffusion de documents scientifiques de niveau recherche, publiés ou non, émanant des établissements d'enseignement et de recherche français ou étrangers, des laboratoires publics ou privés. 


\title{
Changes in atmospheric sulfur burdens and concentrations and resulting radiative forcings under IPCC SRES emission scenarios for 1990-2100
}

\author{
M. Pham \\ Service d'Aéronomie, IPSL, CNRS/UPMC, Paris, France \\ O. Boucher ${ }^{1}$ \\ Laboratoire d'Optique Atmosphérique, CNRS/USTL, Villeneuve d'Ascq, France \\ D. Hauglustaine \\ Laboratoire des Sciences du Climat et de l'Environnement, IPSL, CEA/CNRS, Gif sur Yvette, France
}

Received 14 June 2004; revised 5 November 2004; accepted 28 January 2005; published 25 March 2005.

[1] Simulations of the global sulfur cycle under the IPCC SRES scenarios have been performed. Sulfur dioxide and sulfate burdens, as well as the direct and first indirect radiative forcing (RF) by sulfate aerosols only, are presented for the period 1990 to 2100. By 2100, global sulfur emission rates decline everywhere in all scenarios. At that time, the anthropogenic sulfate burden ranges from 0.34 to 1.03 times the 1990 value of $0.47 \mathrm{Tg} \mathrm{S}$. Direct and indirect global and annually mean RFs relative to the year 1990 are near 0 or positive (range of -0.07 to $0.28 \mathrm{Wm}^{-2}$ and 0.01 to $0.38 \mathrm{Wm}^{-2}$ for the direct and indirect effects, respectively). For reference these forcings amount respectively to -0.42 and $-0.79 \mathrm{Wm}^{-2}$ in 1990 relative to preindustrial conditions (around 1750). Sulfur aerosols will therefore induce a smaller cooling effect in 2100 than in 1990 relative to preindustrial conditions. For the period 1990 to 2100, the forcing efficiencies (computed relatively to 1990) are fairly constant for the direct effect (around $\left.-160 \mathrm{~W}(\mathrm{~g} \text { sulfate })^{-1}\right)$. The forcing efficiencies for the indirect effect are around -200 and $-100 \mathrm{~W}$ (g sulfate) ${ }^{-1}$ for negative and positive burden differences,

respectively. This is due to a shift in regional patterns of emissions and a saturation in the indirect effect. The simulated annually averaged $\mathrm{SO}_{2}$ concentrations for $\mathrm{A} 1 \mathrm{~B}$ scenario in 2020 are close to air quality objectives for public health in some parts of Africa and exceed these objectives in some parts of China and Korea. Moreover, sulfate deposition rates are estimated to increase by $200 \%$ from the present level in East and Southeast Asia. This shows that Asia may experience in the future sulfur-related environmental and human health problems as important as Europe and the United States did in the 1970s.

Citation: Pham, M., O. Boucher, and D. Hauglustaine (2005), Changes in atmospheric sulfur burdens and concentrations and resulting radiative forcings under IPCC SRES emission scenarios for 1990-2100, J. Geophys. Res., 110, D06112, doi:10.1029/2004JD005125.

\section{Introduction}

[2] Aerosol concentrations and radiative forcings (RF) will change in the future as a result of changing emissions and changing climate. It has been now established that anthropogenic activities have largely increased the concentrations of a number of atmospheric trace gases and aerosols. Aerosols derived from fossil fuel, biomass burning and natural sources absorb and reflect solar radiation, which in general leads to a cooling of the climate system. In addition, changes in aerosol concentrations can alter cloud amount

\footnotetext{
${ }^{1}$ Now at Hadley Centre for Climate Prediction and Research, Met Office, Exeter, UK.

Copyright 2005 by the American Geophysical Union. 0148-0227/05/2004JD005125
}

and cloud reflectivity through their effect on cloud properties and lifetime. The radiative effects of sulfate aerosols during the 1860 to 1990 period have been estimated by Myhre et al. [2001] and Boucher and Pham [2002]. In the context of the detection of anthropogenic climate change, it is important to determine the impact of the sulfate aerosol forcing (and more generally the aerosol forcings) on future climate change [Penner et al., 2001; Ramaswamy et al., 2001; Anderson et al., 2003]. This paper contributes to evaluate the climatic consequences of alternative future emissions (in the absence of specific measures to reduce them) and to provide input for further studies or assessment of emission reduction strategies.

[3] There has also been a lot of concern about anthropogenic sulfur emissions because of the consequences on air quality and acid rain. Targets for reductions in emission and 
air quality standards have been fixed at national and international levels. Control strategies have been performed especially in Europe and North America through a number of protocols under the Convention on Long-Range Transboundary transport of Air Pollutants (CLRTAP) and the acid rain programme of the Environmental Protection Agency (EPA) [e.g., Economic Commission for Europe (ECE), 2002; EPA, 1999]. Although the situation has improved in North America and Europe, there are still some ecosystems which suffer from acid rain [Driscoll et al., 2001]. It has been recognised more recently that acidic deposition has also affected ecosystems in China and other areas of the world. The deposition of "potential acidity" (which takes into account the microbial transformation of ammonium to nitrate in saturated terrestrial ecosystems) has been calculated to be maximum over Europe, eastern North America, southern China, but also India, Bangladesh as well as smaller areas all over the world [Rodhe et al., 2002]. The estimate of acidic deposition and $\mathrm{SO}_{2}$ levels for future emission scenarios is therefore important to assess the environmental effects of different energy production and emission scenarios.

[4] Past emissions are known to a certain degree of accuracy and several emission inventories have been made available for sulfur dioxide [Örn et al., 1996; Lefohn et al., 1999; van Aardenne et al., 2001] and fossil-fuel black carbon aerosols [Novakov et al., 2003]. Emissions are nevertheless the product of complex dynamic processes involving demographic, socio-economic, technological, and institutional changes. The future of these factors is highly uncertain and might lead to very different development patterns. We use a set of gridded emissions based on the Intergovernmental Panel on Climate Change (IPCC) Special Report on Emission Scenarios (SRES) [Nakićenović et al., 2000] which correspond to different scenarios from 1990 to 2100 . These scenarios have been developed specifically to provide self-consistent and up-to-date scenarios for climate modeling. Although the assumptions behind the SRES emissions scenarios are still under debate [Hansen, 2004], these scenarios remain widely used and no alternative scenarios for $\mathrm{SO}_{2}$ exist yet. Our results, which are restricted to sulfate aerosols, are therefore valid within the assumptions of the SRES scenarios and the model limitations. Although it is beyond the scope of this study to discuss the quality of the scenarios, we will discuss their implications in terms of radiative effects, sulfur deposition, and air quality.

[5] Despite the uncertainties associated with the modeled present-day distributions of aerosol concentrations and radiative forcings [Penner et al., 2001; Ramaswamy et al., 2001], general circulation models (GCMs) include the relevant chemical, physical, and dynamical processes needed to estimate the future changes in aerosol concentrations and to explore the uncertainties associated with future emissions. We calculate sulfate distributions and sulfate aerosol RFs within the Laboratoire de Météorologie Dynamique (LMD) GCM. We present results on sulfur deposition fluxes, sulfate concentrations and burdens, and direct and first indirect radiative effects for the period from 1990 to 2100. This study extends the history simulations described in Boucher and Pham [2002]. The anthropogenically forced climate response has also been examined over the period
1860 to 2100 by Johns et al. [2003] using the SRES emissions and the HadCM3 coupled model. These authors recognized that the global residence time of anthropogenic sulfate aerosol in their model is too low, leading to direct radiative forcings which are also too low. For this reason we will not compare our results with those of Johns et al. [2003].

\section{Description of the Model}

[6] We use the sulfur cycle model implemented in the LMD GCM. The general features of the model are described in Boucher et al. [2002]. Six sulfur species are chemical prognostic variables of the model while hydrogen peroxide can be considered as a semi-prognostic variable. The concentrations of these variables are computed using prescribed present-time fields of oxidants and photodissociation rates. In this version the oceanic DMS emissions are calculated with the parametrization of Nightingale et al. [2000] and amounts to $26.4 \mathrm{TgS} \mathrm{yr}^{-1}$ in global and annual average. Specific points related to the radiative forcing calculations are given in Boucher and Pham [2002]. The model has been evaluated and used in several studies [e.g., Boucher et al., 2002, 2003].

[7] In our simulations sulfate aerosols do not feedback on the radiation and cloud fields (i.e., sulfate radiative effects are purely diagnostic) so that all simulations have the same meteorology. We consider that neither the oxidant fields (except $\mathrm{H}_{2} \mathrm{O}_{2}$ which is calculated semi-interactively in our model from prescribed $\mathrm{OH}, \mathrm{HO}_{2}$, and photodissociation rates) nor the natural sources of sulfur species (including volcanoes) have changed during the period under study. Results are presented as annual averages after a 6 month spin up time. We do not include here the radiative effects of aerosol types other than sulfate because of the lack of future emission scenarios for these species. Only the direct effect and first indirect effect, whereby an increase in aerosols causes an increase in droplet concentration and a decrease in droplet size for fixed liquid water content [Twomey, 1974], are estimated here.

\section{SRES Emissions}

[8] SRES scenarios are divided into four families or storylines corresponding to different assumptions on the demographic, social, technological, and economic development of the different regions of the world as well as the concern in the protection of local and regional environments for each region. The A1 scenario family describes a future world of very rapid economical growth, global population that peaks in the mid-century and decline thereafter, and the rapid introduction of new and more efficient technologies. It develops into 3 groups using alternative directions of technological ways in the energy system: fossil intensive energy sources (A1FI), nonfossil energy sources (A1T), and a balance across all sources (A1B). The A2 scenario family describes a very heterogeneous world with continuously increasing population. Per capita economic growth and technological changes are more fragmented and slower than in other storylines. The B1 scenario family describes a world with the same global population as in the A1 storyline but with the introduction 


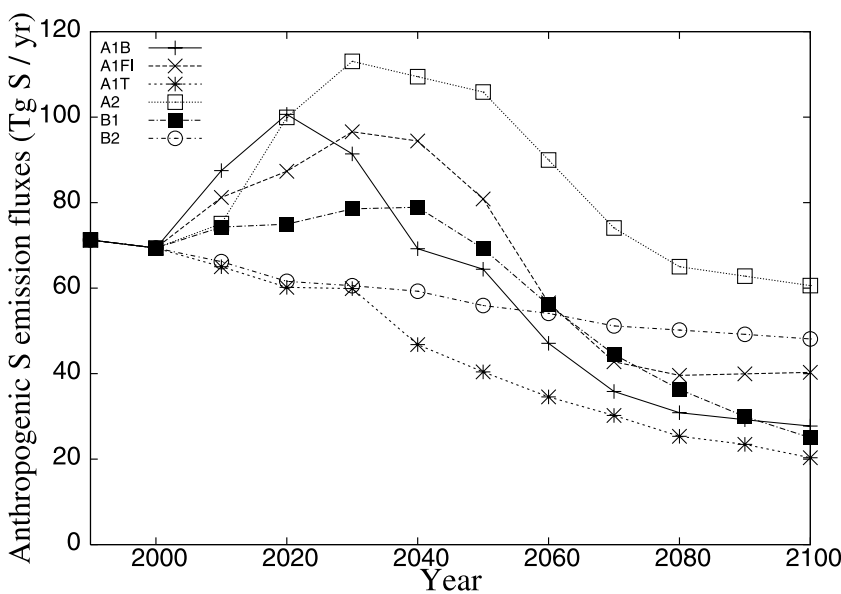

Figure 1. Global- and annual-mean emissions of anthropogenic sulfur $\left(\mathrm{Tg} \mathrm{S} \mathrm{yr}^{-1}\right)$ under the 6 SRES scenarios.

of clean and resource efficient technologies and reductions in material intensity. The B2 scenario family describes a world with continuously increasing global population, intermediate levels of economic development and oriented towards environmental protection and social equity. Full description of these scenarios is given in Nakićenović et al. [2000].

[9] For each scenario, emission estimates for radiatively important gases including greenhouse gases, ozone precursors, and sulfur dioxide span the interval 1990 to 2100. Emission values are standardized for 1990 and 2000 and are common to all the scenarios. In this study we use the sulfur SRES emissions of the 6 "markers" described above. Anthropogenic sulfur is emitted 95\% as $\mathrm{SO}_{2}$ and the remaining $5 \%$ as sulfate aerosols. We also account for an additional source of anthropogenic sulfur under the form of $\mathrm{H}_{2} \mathrm{~S}$, which amounts to $4.26 \%$ of industrial $\mathrm{SO}_{2}$ according to Boucher et al. [2002]. In the absence of data both industrial $\mathrm{SO}_{2}$ and $\mathrm{H}_{2} \mathrm{~S}$ are emitted at the surface. Figure 1 illustrates the global anthropogenic sulfur emission rates for the different scenarios and years, while Table 1 summarizes these values for 1990, 2100 , and the year of maximum emission rate of each scenario. Except for the B2 and A1T scenarios where emissions continuously decrease, all scenarios present a peak followed by a rapid decrease which tends to slow

Table 1. Global Anthropogenic Emission Rates for 1990, 2100, 2050, and the Year of Maximum Rate Referred to as Yearmax and Given in Parenthesis ${ }^{\mathrm{a}}$

\begin{tabular}{lccccccc}
\hline & \multicolumn{3}{c}{ Global Scenario Orientation } & & \multicolumn{2}{c}{ Local Orientation } \\
\cline { 2 - 5 } \cline { 3 - 5 } Scenario & A1B & A1FI & A1T & B1 & & A2 & B2 \\
\hline 1990 & 71 & 71 & 71 & 71 & & 71 & 71 \\
Yearmax & $(2020)$ & $(2030)$ & $(1990)$ & $(2040)$ & & $(2030)$ & $(1990)$ \\
& 101 & 97 & 71 & 79 & & 113 & 71 \\
2050 & 64 & 81 & 40 & 69 & & 106 & 56 \\
2100 & 28 & 40 & 20 & 25 & & 61 & 48 \\
\hline
\end{tabular}

${ }^{\mathrm{a}}$ Units are in $\mathrm{Tg} \mathrm{S} \mathrm{yr}^{-1}$.

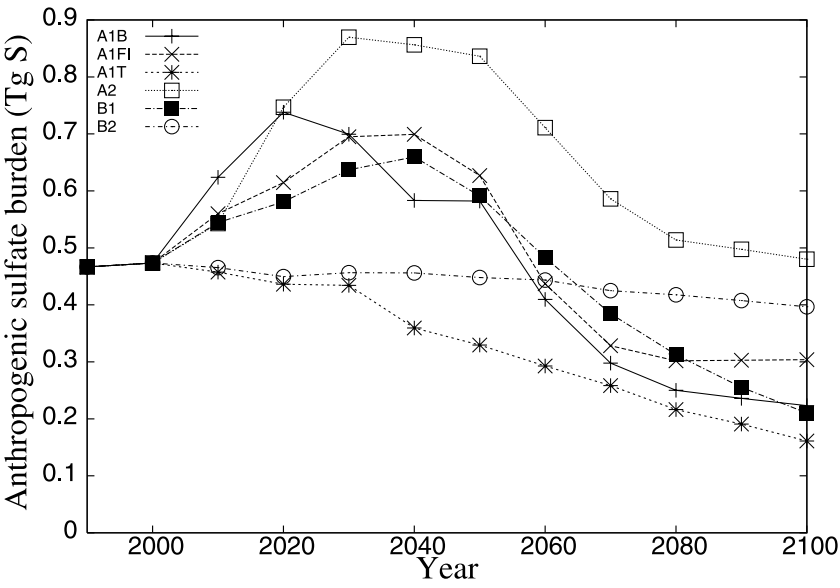

Figure 2. Global and annual-mean anthropogenic sulfate burden (Tg S) simulated by the model for the period 1990 to 2100 under the 6 SRES scenarios.

down around 2080. Sulfur emission rates in 2100 are 29 to $85 \%$ of the 1990 value.

\section{Results}

\subsection{Sulfate Burdens}

[10] As shown in Figure 2, the burden of anthropogenic sulfate follows a similar temporal evolution to emissions ranging from 0.16 to $0.48 \mathrm{Tg} \mathrm{S}$ in 2100 (i.e., 0.34 to 1.03 times the 1990 value of $0.47 \mathrm{Tg} \mathrm{S}$, depending on the scenario). This burden reaches a maximum value of $0.87 \mathrm{Tg} \mathrm{S}$ in 2030 for scenario A2 or almost twice the 1990 value. In 2050 which experiences the largest spread in global emission values, the anthropogenic sulfate burden ranges from 0.33 to $0.83 \mathrm{Tg} \mathrm{S}$. Although sulfate production is based on the availability of oxidants and $\mathrm{SO}_{2}$, there is a gross linear relationship between the anthropogenic sulfate burden and the sulfur emission on a global scale (Figure 3). However, it should be noted that we did not model neither the change in oxidant concentrations due to changing emissions nor the variations of aerosol and oxidant concentrations in response to climate change and their consequent impact on the $\mathrm{S}$ burden. A short discussion of these effects is included in section 5 .

[11] The regional distribution of sulfate experiences large variations across the twenty-first century and among the scenarios, depending on the assumptions concerning the model emissions. Figure 4 shows the sulfate burdens in 2000, 2010, and 2020 for scenario A1B, as well as in 2050 and 2100 for all scenarios.

[12] In 2050, because of sulfur control policies in the industrialized regions and the economic development in Russia and Eastern Europe, sulfur emissions have passed their peaks and decline except for the A2 scenario which considers an increased use of coal. Large values of sulfate burden are found also in the A2 scenario in India, China, Southeast Asia, while emissions in these areas have already declined at that time in the other scenarios. This is particularly the case in the A1B scenario where low-sulfur technologies and fuel switching were rapidly introduced in Central and South Asia. Over Africa, values of sulfate burdens vary from 3 to $10 \mathrm{mg} \mathrm{S} \mathrm{m}^{-2}$ for scenarios A1B, 


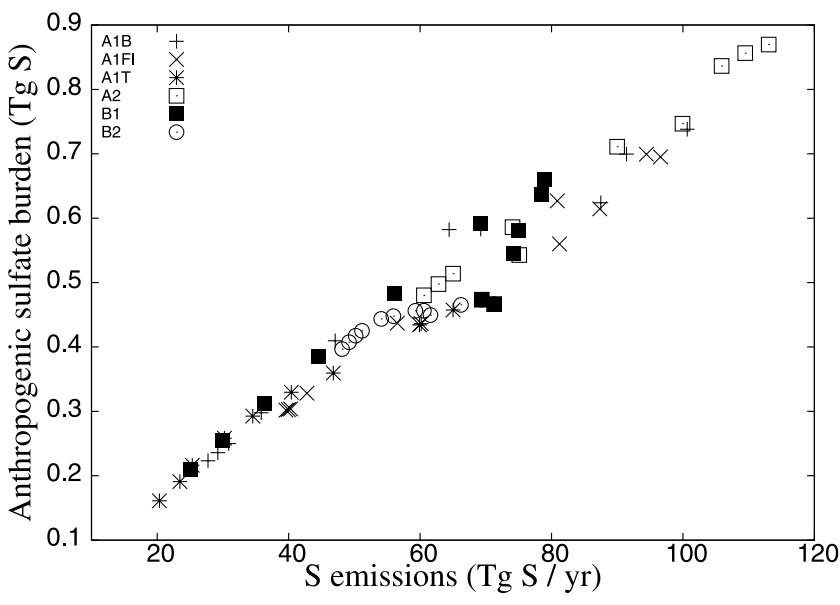

Figure 3. Global- and annual-mean anthropogenic sulfate burden (Tg S) as a function of anthropogenic sulfur emission $\left(\mathrm{Tg} \mathrm{S} \mathrm{yr}^{-1}\right)$ for all scenarios.

A1FI, A2, and B1, while they are less than $3 \mathrm{mg} \mathrm{S} \mathrm{m}^{-2}$ for $\mathrm{A} 1 \mathrm{~T}$ and $\mathrm{B} 2$ on average. This reflects also the patterns in $\mathrm{SO}_{2}$ emissions in Africa which combines countries with different development trends.

[13] By 2100, low sulfur-emission technology is assumed to be accessible everywhere for all scenarios and global emission rates decline in all storylines. However, there is still an hemispheric contrast which is opposite to that of the 1990s. The ratio of sulfate burdens in 2100 to 1990 is less than 0.8 north to $10^{\circ} \mathrm{N}$ for almost all scenarios and less than 1 south to $10^{\circ} \mathrm{N}$, except for Africa and parts of the adjoining Atlantic and Indian Oceans, where it can reach values in the range of 1.5 to 2.5 .

\subsection{Radiative Forcings}

[14] If not stipulated otherwise, RFs have been calculated relative to the year 1990. All simulations have the same meteorology and there is no feedback on the radiation and cloud fields as specified in section 2. The time evolution of the RFs by sulfate aerosols is represented on Figure 5. The direct RFs roughly follow the burdens, decreasing linearly when the anthropogenic burden increases and inversely. This is not the case for the indirect RFs which presents some strong nonlinearities. For instance, the indirect RFs for scenario B1 are larger in absolute value than their A1FI counterparts from 2000 to 2060 , while the anthropogenic sulfate mass is smaller in the B1 scenario for these years. The range of variation in the global- and annual-mean RFs for the different scenarios in 2100 is -0.07 to $0.28 \mathrm{Wm}^{-2}$ and 0.01 to $0.38 \mathrm{Wm}^{-2}$ for the direct and indirect effects, respectively. Sulfate aerosols will therefore induce less cooling in 2100 than in 1990 relative to preindustrial times.

[15] While the direct RF by sulfate aerosols in 1990 relative to preindustrial conditions (1750) is roughly half the indirect RF [Boucher and Pham, 2002], this is not the case for the additional RF in 2000-2100 relative to 1990. Because of the saturation of the indirect RF, both RFs are of similar magnitude. We follow Boucher and Pham [2002] and calculate the radiative forcing by unit mass of sulfate (radiative forcing efficiency). We discuss first the RF efficiency relative to preindustrial conditions (Figure 6a).
It is estimated to be -153 and $-288 \mathrm{~W}$ (g sulfate) ${ }^{-1}$ in 1990 for the direct and indirect effects, respectively. Whichever scenario is considered, the RF efficiency for the direct effect remains fairly constant over time. However, the strong nonlinearities induced by the aerosol to cloud droplet number concentration (CDNC) and CDNC to cloud albedo relationships imply a large variation in the RF efficiency for the indirect effect (from about -440 to $-210 \mathrm{~W}$ ( $\mathrm{g}$ sulfate) ${ }^{-1}$ for burdens ranging from 0.2 to $0.85 \mathrm{Tg} \mathrm{S}$ ).

[16] When computed relative to 1990, the RF efficiency for the direct effect is also around $-160 \mathrm{~W}$ (g sulfate) ${ }^{-1}$ except for small changes in burdens, in which case smaller and larger values are observed (Figure 6b). These cases correspond to a shift in the geographical patterns of emissions between regions of large and small RF efficiencies. Depending on the sign of the net change in burden, the RF efficiency can be either larger or smaller than the typical value of $-160 \mathrm{~W}$ (g sulfate) $)^{-1}$. The RF efficiency for the indirect effect relative to 1990 exhibits the same kind of behaviour than for the direct effect but with more scatter (Figure 6c). For positive change in burden, the RF efficiency is systematically smaller (in magnitude), partly because of the saturation of the indirect effect, and can even get positive.

[17] The spatial distributions of the two aerosol RFs are illustrated on Figure 7 for scenario A1B only over the period from preindustrial to 2020 and over the period 1990 to 2020. Direct and indirect RFs are negative for the first period but present very different distributions. The direct $\mathrm{RF}$ is smaller than $-1 \mathrm{Wm}^{-2}$ over most continental areas (Eastern North America, Europe, Africa, Asia) and reaches minima values of around $-4 \mathrm{Wm}^{-2}$ over Southeast Asia and India, following the pattern of sulfur anthropogenic emissions. The indirect RF is more widely distributed since it depends non linearly on the cloud cover, the liquid water content, and the CDNC estimated from the sulfate aerosol mass. It easily reaches $-1 \mathrm{Wm}^{-2}$ in the same regions and large oceanic areas especially in the Northern hemisphere. Patterns are different when one looks at the RF values relatively to 1990. Direct RFs are positive in Europe, Russia, and North America, with values reaching more than $1 \mathrm{Wm}^{-2}$ following the use of low sulfur-emission technologies in these areas. Over Africa and Asia, however, direct and indirect RFs are negative.

\subsection{Surface Concentrations and Deposition Fluxes}

[18] We also looked at surface concentrations of $\mathrm{SO}_{2}$ in relation to air quality standards. The present resolution of the model $\left(3.75^{\circ} \times 2.5^{\circ}\right)$ does not allow any accurate assessment of air quality issues at the urban scale. Modelpredicted $\mathrm{SO}_{2}$ concentrations are grid-box values which represent an average over several hundred square kilometers. We do not have quantitative data on the sub-grid scale variability of $\mathrm{SO}_{2}$ concentrations at the model resolution. It is known, however, that at least over Europe, $\mathrm{SO}_{2}$ concentrations exceed thresholds at very small scales (i.e., around very industrialized parts of cities). It is clear that if background values at the resolution of our model are large, then it is likely that $\mathrm{SO}_{2}$ concentrations get above the exceedance levels in urban or industrialized areas. As shown in Figure 8a, the maximum 24-hour averaged $\mathrm{SO}_{2}$ concentrations at the surface come at about $30 \mathrm{ppbv}$ (or 
(a)

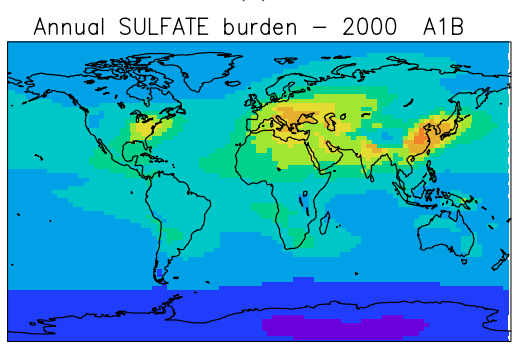

(d)

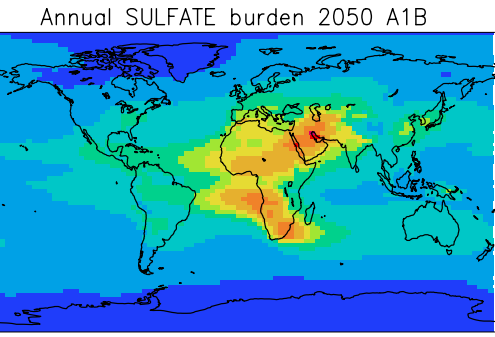

(g)

Annual SULFATE burden 2050 A2

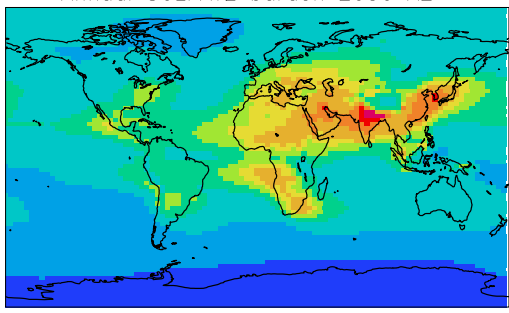

(j)

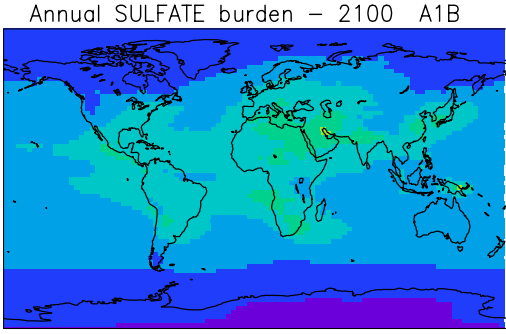

(m)

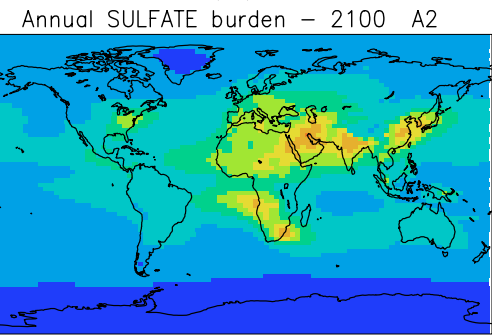

(b)

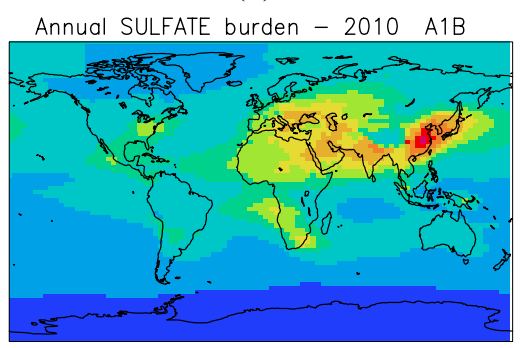

(e)

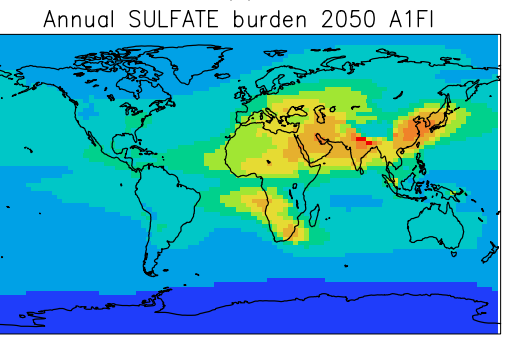

(h)

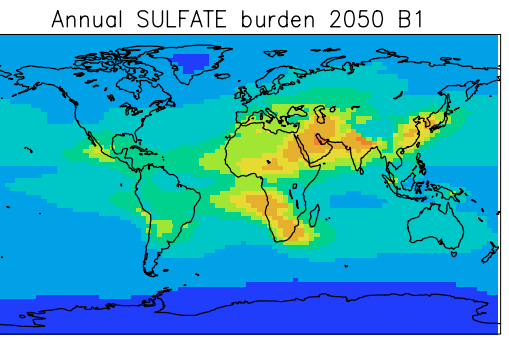

(k)

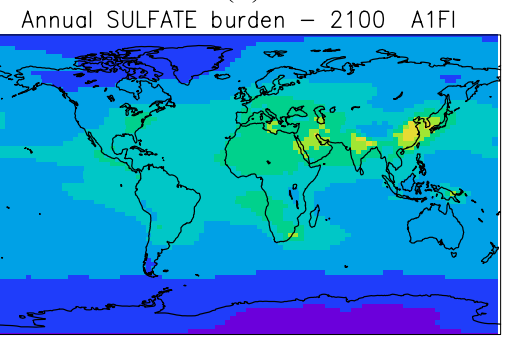

(n)

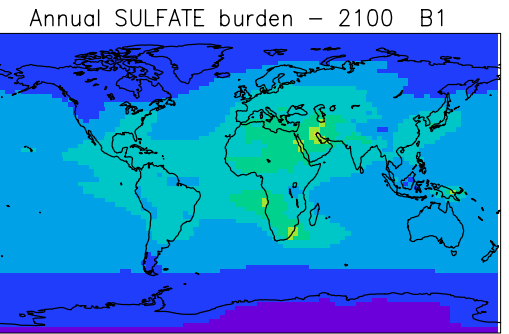

(c)

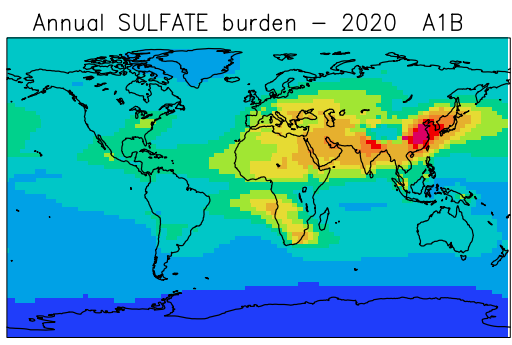

(f)

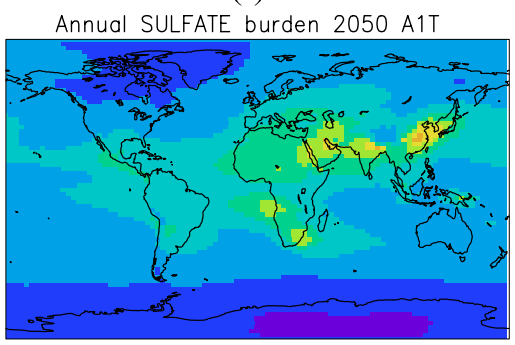

(i)

Annual SULFATE burden 2050 B2

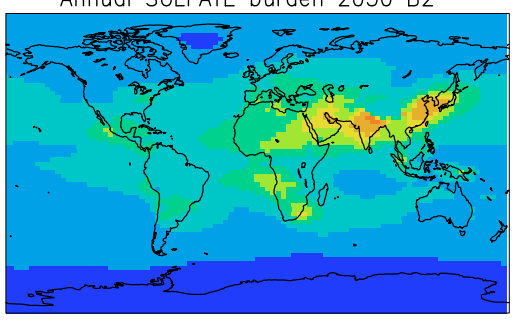

(1)

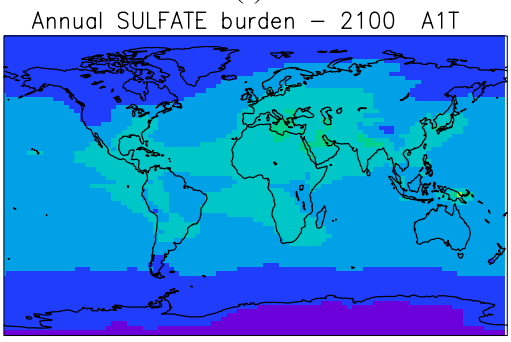

(o)

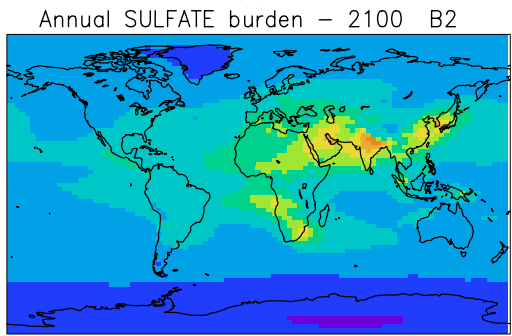

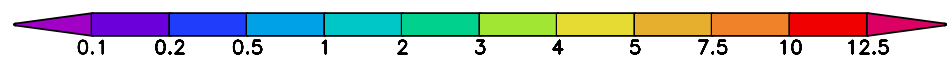

Figure 4. Annual-mean anthropogenic sulfate burden ( $\mathrm{mg} \mathrm{S} \mathrm{m}^{-2}$ ) in (a) 2000, (b) 2010, (c) 2020 for A1B, (d)-(i) 2050 for A1B, A1FI, A1T, A2, B1, and B2 scenarios, respectively, and (j)-(o) 2100 for A1B, A1FI, A1T, A2, B1, and B2 scenarios, respectively. 

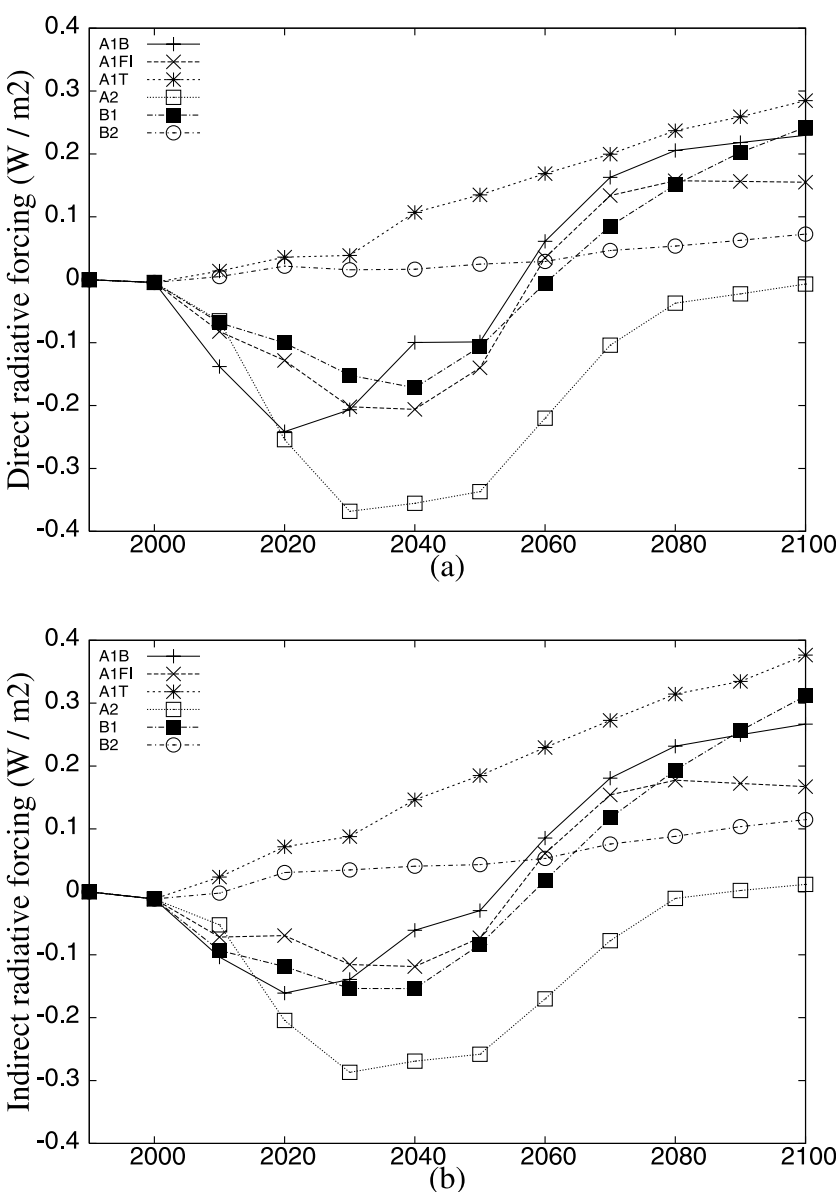

Figure 5. Time evolution of the global- and annual-mean (a) direct and (b) first indirect RFs by sulfate aerosols $\left(\mathrm{W} \mathrm{m}^{-2}\right.$ ) relative to 1990 for all scenarios.

about $80 \mu \mathrm{g} \mathrm{SO}_{2} \mathrm{~m}^{-3}$ ) in 2020 in East China under scenario A1B. This corresponds to a three-fold increase compared to the base year 1990 in the same area. For comparison regulations in France and the United States give alert thresholds to protect public health at $125 \mu \mathrm{g} \mathrm{SO}_{2} \mathrm{~m}^{-3}$ not to be exceeded more than $0.8 \%$ of the time (data available at $\mathrm{http}: / / \mathrm{www}$.airparif.asso.fr) and around $370 \mu \mathrm{g} \mathrm{SO}_{2} \mathrm{~m}^{-3}$ not to be exceeded more than once per year on a daily average (data available at http://www.epa.gov). Although our maximum background 24-hour averaged $\mathrm{SO}_{2}$ concentrations at the surface do not exceed these ambient air quality standards for public health at the model resolution, it is therefore likely that the thresholds be exceeded at the local scale.

[19] Annually averaged $\mathrm{SO}_{2}$ concentrations for scenario A1B in 2020 are also near or exceed the French air quality objective of $50 \mu \mathrm{g} \mathrm{SO}_{2} \mathrm{~m}^{-3}$ - for comparison, the standard is $80 \mu \mathrm{g} \mathrm{SO}_{2} \mathrm{~m}^{-3}$ in the United States - in some parts of Africa and Eastern Asia (Figure 8b). These concentrations are also above the European standards required for protection against damage to ecosystems $\left(20 \mu \mathrm{g} \mathrm{SO}_{2} \mathrm{~m}^{-3}\right.$ on the annual mean) in parts of South Africa, India and Eastern Asia.

[20] In order to estimate the harmful effects of acid deposition, one usually uses the concept of critical load which represents the maximum long-term deposition levels which can be tolerated by sensitive ecosystems without damage [Nilsson and Greenfelt, 1988]. It is out of the scope of this study to calculate critical loads since this assessment is generally based on complex dynamic models describing processes in key ecosystems including soils, surface waters,

(a)

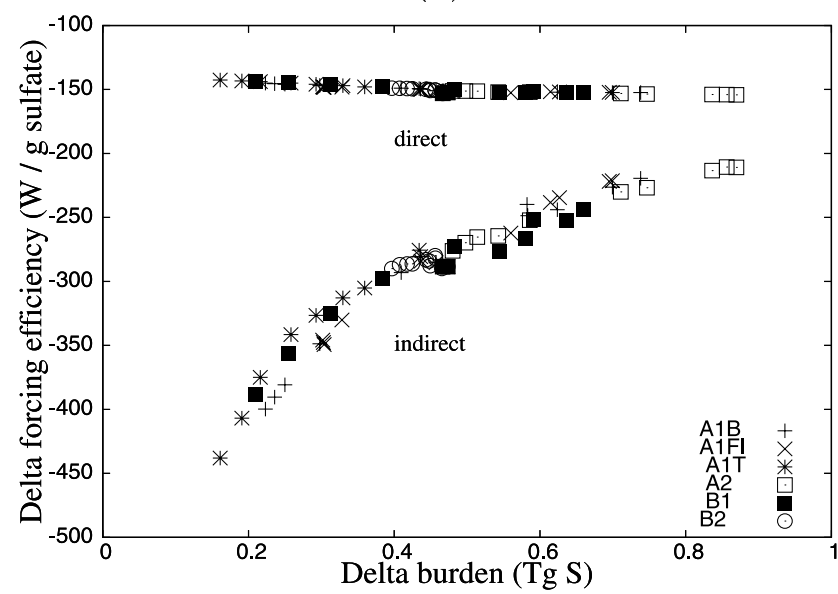

(b)

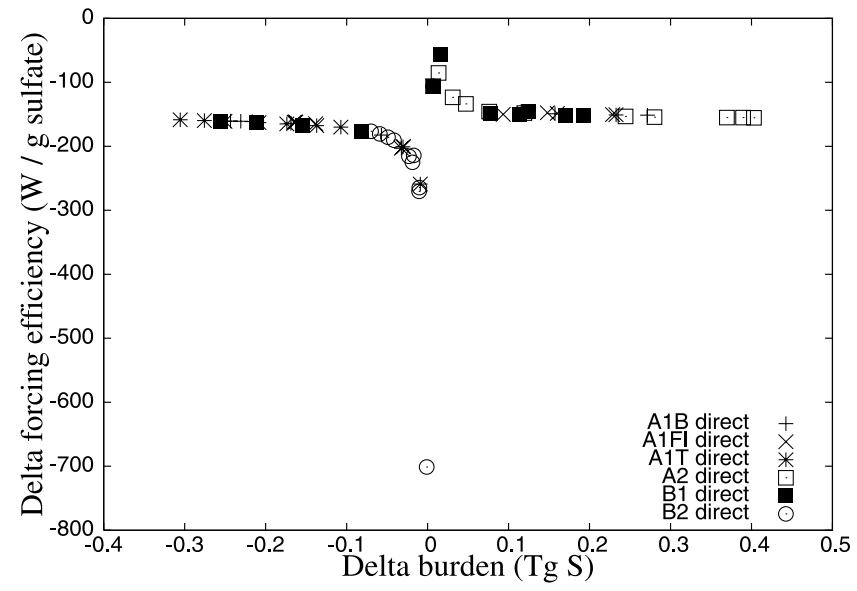

(c)

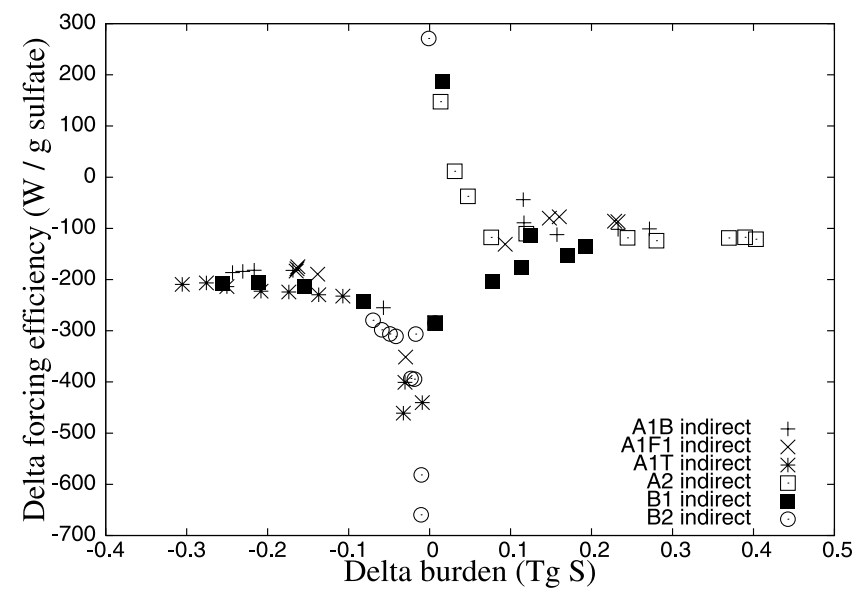

Figure 6. Forcing efficiencies (W (g sulfate $)^{-1}$ ) for the direct and first indirect RFs by sulfate aerosols as a function of the anthropogenic sulfate burden (Tg S) for all scenarios (a) relative to preindustrial times, (b) relative to 1990 for the direct RF, and (c) relative to 1990 for the first indirect RF. 
Direct radiative forcing $(W m-2)$ A1B 2020 -natural

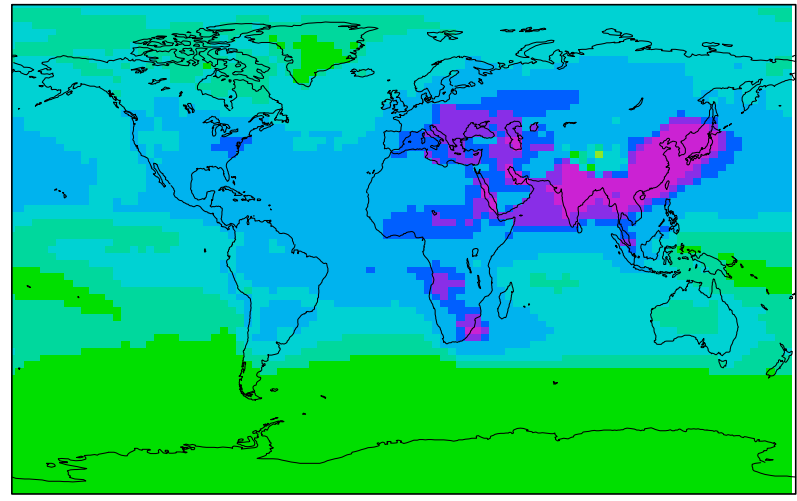

Direct radiative forcing $(\mathrm{Wm}-2)$ A1B $2020-1990$

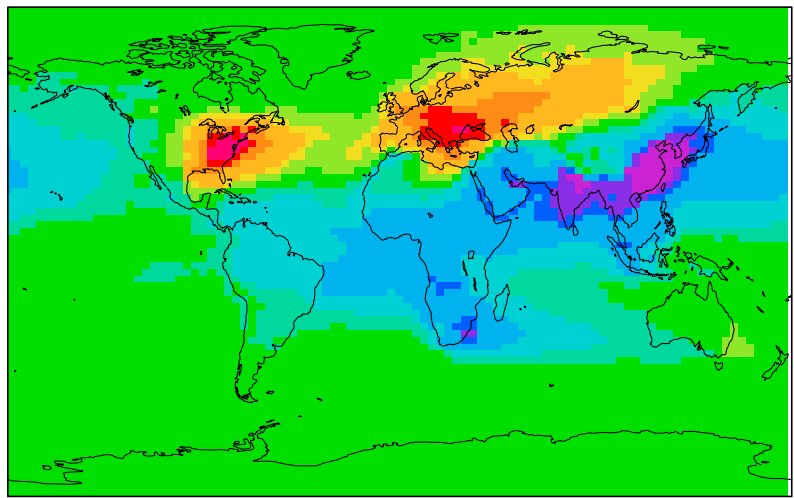

Indirect radiative forcing (Wm-2) A1B 2020-natural

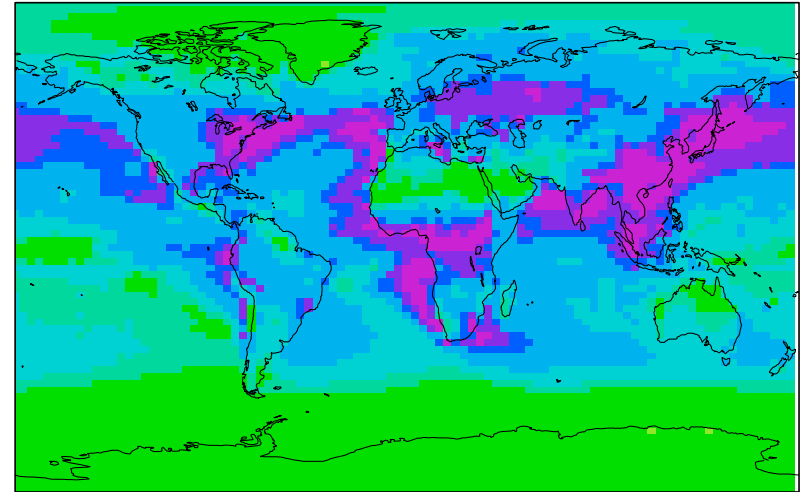

Indirect radiative forcing (Wm-2) A1B 2020-1990

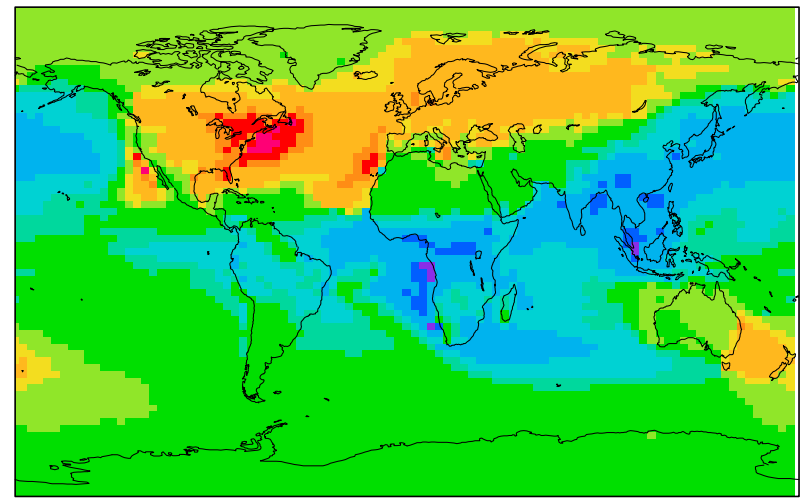

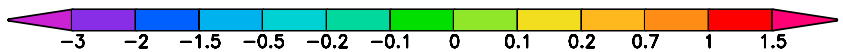

Figure 7. Direct and indirect RFs by sulfate aerosols in 2020 relative to preindustrial conditions (top panels) and relative to 1990 (bottom panels) for the A1B scenario only.

and vegetation systems [e.g., Hettelingh et al., 1995]. Although the rate of acidic deposition depends on a balance between the deposition rates of at least four components $\left(\mathrm{SO}_{x}\right.$, $\mathrm{NO}_{y}, \mathrm{NH}_{x}$, and Ca) [Rodhe et al., 2002], we simply report here the sum of dry and wet deposition fluxes of oxidized sulfur. Deposition fluxes as large as 2 to $5 \mathrm{~g} \mathrm{~S} \mathrm{~m}^{-2} \mathrm{yr}^{-1}$ are predicted in 2020 over China under scenario A1B (Figure 9b). This is an increase of a factor of 2 to 3 compared to 1990 levels in these areas (compare to Figure 9a). In Asia more specifically, there is a growing concern about acid rain, as emissions of $\mathrm{SO}_{2}$ and $\mathrm{NO}_{x}$ from the combustion of fossil fuels increase and coal is the dominant energy source. The RAINS-ASIA project has been developed to answer to the threat of acid rain and more generally the problem of transboundary pollution in the Asian continent, and integrates assessment of future $\mathrm{SO}_{2}$ emissions in Asia and calculations of critical loads of several pollutants [Shah et al., 2000]. As an example, critical loads calculated by RAINS-ASIA at (a)

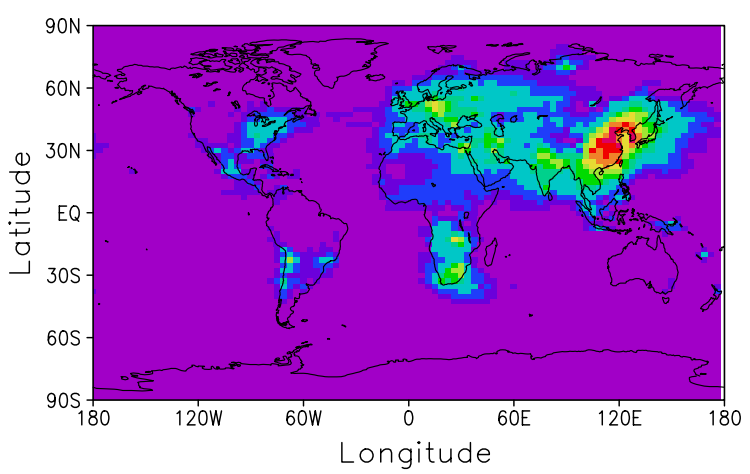

(b)

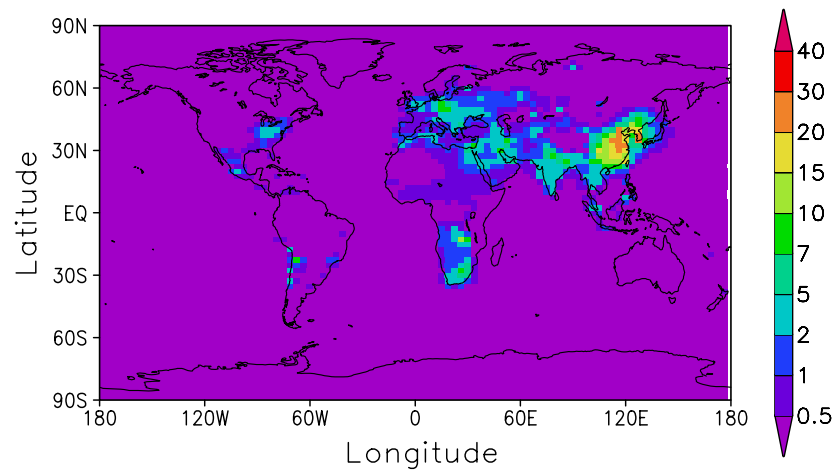

Figure 8. (a) Maximum 24-hour averaged and (b) annually averaged $\mathrm{SO}_{2}$ concentrations (ppbv) at the surface in 2020 for the A1B scenario. 
(a)

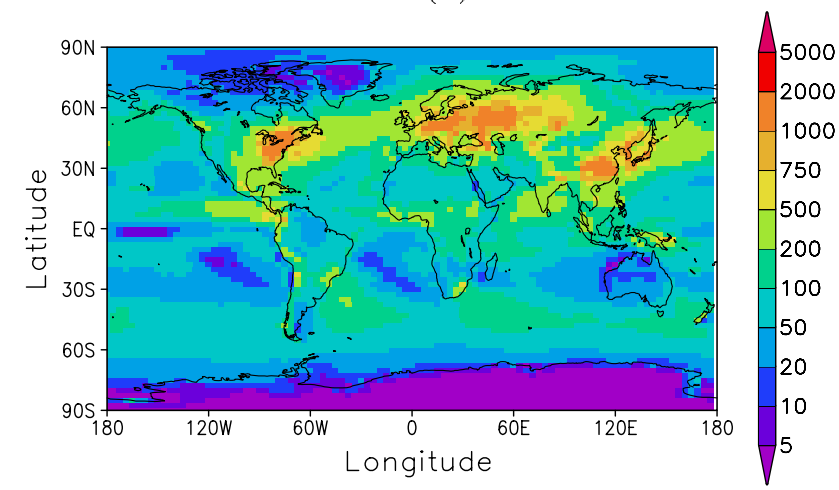

(b)

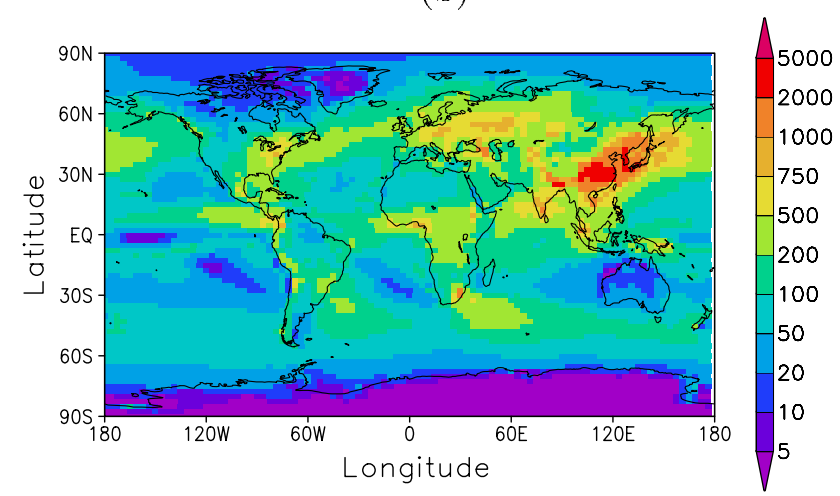

Figure 9. Annual-mean sulfur deposition $\left(\mathrm{mg} \mathrm{S} \mathrm{m}^{-2}\right.$ ) in (a) 1990 and (b) 2020 for the A1B scenario.

25th percentile (Guttikunda, private communication) are exceeded by LMD-Z sulfur deposition (A1B scenario in 2020) in large parts of Eastern China, South India, Southeast Asia, Japan, and Korea.

[21] Because of the large threat on ecosystems from both atmospheric concentrations of sulfur dioxide and deposition flux of oxidized sulfur under some of the SRES scenarios in 2020 , one can raise the question of the realism of the large emission fluxes over Asia. It is likely that mitigation policies on sulfur dioxide emissions will be implemented to prevent such large concentrations and deposition fluxes inasmuch as the technology already exists.

\section{Discussion of Uncertainties}

[22] We discuss here a number of uncertainties related to this modeling work. As already mentioned, our results are valid within the assumptions on the SRES emissions that we will not discuss here and within the limit of our sulfur model. The sulfur cycle in the LMD GCM has been extensively documented and validated for surface concentrations, vertical profiles, and deposition rates over different geographical locations in Boucher et al. [2002]. The surface concentrations and deposition rates are in good agreement with many measurements. Surface concentrations of sulfates are underestimated during wintertime in Europe due to biases in the GCM climatology of cloud cover and precipitation as well as too low oxidants levels during winter. The sensitivity to some of the model parameters has also been investigated in previous papers. Boucher et al. [2003] show among other results that DMS distributions depend critically on the prescribed oxidant fields and that oxidation by $\mathrm{O}_{3}$ is important at high latitudes in both hemispheres.

[23] Our simulations are for fixed concentrations of oxidants (except $\mathrm{H}_{2} \mathrm{O}_{2}$ which is semi-prognostic). In order to test the impact of this assumption, we performed a sensitivity study to the concentrations of oxidants. The fields of $\mathrm{OH}, \mathrm{HO}_{2}, \mathrm{O}_{3}$, and $\mathrm{NO}_{3}$ have been calculated using the SRES emissions of oxidant precursors for 2000 and for year 2100 of scenario A2 in the model of Hauglustaine et al. [2004]. These oxidant fields are then used in a new set of simulations performed with our model of the sulfur chemistry only. They are characterized by larger concentrations of $\mathrm{OH}$ over the continents, larger concentrations (by up to $30 \mathrm{ppbv}$ ) of $\mathrm{O}_{3}$, and larger concentrations of $\mathrm{HO}_{2}$, which also results in larger concentrations of $\mathrm{H}_{2} \mathrm{O}_{2}$. We discuss here the results of two additional simulations: (1) a simulation prescribing oxidant fields of year 2000 but using SRES sulfur emissions of year 2100 of scenario A2 (referred to as INCA XX) and (2) a simulation prescribing oxidant fields of year 2100 of scenario A2 and using SRES sulfur emissions of year 2100 of scenario A2 (referred to as INCA XXI). We can therefore examine the impact due to changes in the oxidants between years 2000 and 2100 for the extreme case of scenario A2.

[24] Surface concentrations and columns of $\mathrm{SO}_{2}$ and sulfate from simulations INCA XX and INCA XXI show the same regional distributions with maxima values over Northeast America, Europe, Middle East, India, East Asia, and Southern Africa, thus reflecting the sulfur emission patterns. We observe a global decrease of $22 \%$ and $4-5 \%$ from INCA XX to INCA XXI for the DMS and $\mathrm{SO}_{2}$ burdens, respectively. This is due to more efficient oxidation processes, by $\mathrm{NO}_{3}$ in the case of DMS and $\mathrm{H}_{2} \mathrm{O}_{2}$ in the case of $\mathrm{SO}_{2}$. However, the sulfate burden does not increase but rather decreases slightly (by less than 1\%). This is due to the more efficient oxidation which places sulfate closer to the surface, where it is more easily deposited and scavenged. The increase in sulfate surface concentrations is of the order of $5 \%$ over a large fraction of the continents. From these two experiments we can conclude that the changes in oxidant fields do not change much the global sulfate budgets because there are already enough oxidants, but they may change DMS concentrations and the vertical distribution of other sulfur species.

[25] Our simulations are for a fixed meteorology, which also introduces an uncertainty as aerosol cycling may respond to climate change. For instance, Feichter et al. [2004] showed that in their model the aerosol lifetime decreases significantly in a warmer climate with a stronger hydrological cycle. Preliminary simulations in our model also show a decrease in sulfate aerosol lifetime but not to such a large extent.

[26] Another important source of uncertainty stems from the representation of the first indirect effect [Penner et al., 2001]. We use an empirical relationship between sulfate mass and the cloud droplet number concentrations. The uncertainty associated to the choice of the relationship is roughly a factor of 2 . Note also that the indirect RF is sensitive to the concentration of background (natural) sul- 
fate aerosols, originating from oxidation of DMS and volcanic $\mathrm{SO}_{2}$, which is not well known.

[27] In the absence of data all anthropogenic sulfur compounds are assumed to be emitted at the surface. However, it could be that the fraction of high $\mathrm{SO}_{2}$ emissions increases in the future as tall stacks are built in the developing countries. If it is the case, this will result in relatively smaller concentrations of $\mathrm{SO}_{2}$ at the surface (and a smaller impact on air quality) than simulated in this study.

\section{Conclusions}

[28] Simulations of the global sulfur cycle under the IPCC SRES scenarios have been performed. We presented $\mathrm{SO}_{2}$ and sulfate burdens, as well as the direct and first indirect RF by sulfate aerosols for the period 1990 to 2100 , within the frame of assumptions made in the SRES scenarios. While these emission scenarios can certainly be refined, it is beyond the scope of this study to discuss the assumptions and quality of the scenarios. Thus, our simulations are valid within the limits of the SRES emissions scenarios and the sulfur model.

[29] In all scenarios, global sulfur emissions rates decline everywhere by 2100 , which is followed by a similar decline (except for the A2 scenario) in the anthropogenic sulfate burden ranging from 0.34 to 0.84 times the 1990 value of $0.47 \mathrm{Tg} \mathrm{S}$ (in the A2 scenario, the 2100 anthropogenic sulfate burden is 1.03 times larger than the 1990 value). In most scenarios maximum emission rates and anthropogenic sulfate burden shift from Europe, Northern America, and Russia towards China, India, Southeast Asia, and Africa before 2050. Direct and indirect RFs relative to the year 1990 are close to 0 or positive by 2100 (range of -0.07 to $0.28 \mathrm{Wm}^{-2}$ and 0.01 to $0.38 \mathrm{Wm}^{-2}$ for the direct and indirect effects, respectively). These values are of the same order of magnitude because of the saturation of the indirect aerosol effect.

[30] There is a lot of scatter in values of the RF efficiency relative to 1990 for burden differences near zero as a small change in the global burden usually masks large regional changes. For burden differences not too small, the RF efficiencies are fairly constant for the direct forcing (around $-160 \mathrm{~W}$ (g sulfate $\left.)^{-1}\right)$. The forcing efficiencies for the indirect forcing are around -200 and $-100 \mathrm{~W}(\mathrm{~g} \text { sulfate })^{-1}$ for negative and positive burden changes, respectively. This can be explained by a shift in emission regions and saturation in the indirect effect.

[31] Using oxidant fields calculated off-line in the model of Hauglustaine et al. [2004] with the SRES emissions of their precursors for 2000 and for year 2100 of scenario A2, we find a general decrease in DMS and $\mathrm{SO}_{2}$ burdens but a very small decrease in the sulfate burden. However, sulfate aerosol surface concentrations experience a significant increase of about $5 \%$ in many regions. The increase in $\mathrm{NO}_{3}$, $\mathrm{O}_{3}$, and $\mathrm{H}_{2} \mathrm{O}_{2}$ concentrations tends to oxidize DMS and $\mathrm{SO}_{2}$ more efficiently and to place more sulfate in the lower layers of the atmosphere.

[32] We did not examine in detail the impacts of sulfur emissions on air quality and ecosystems. However, by looking at $\mathrm{SO}_{2}$ surface concentrations and sulfur deposition rates in the A1B scenario (balance across all sources) in 2020 , we note that the maximum 24-hour averaged $\mathrm{SO}_{2}$ concentrations at the rather coarse model resolution are close to, but do not exceed, ambient air quality standards for public health. Annual means are nevertheless close to air quality objectives of developed countries in some parts of Africa and exceed them in Eastern China and Korea. Annual and seasonal means are also above the standards required for protection against damage to ecosystems in South Africa, India, and Eastern Asia. In East and Southeast Asia more generally, the sulfate deposition rate is estimated to increase by $200 \%$ in 2020 from the present level.

[33] The data presented in this study will be used by a number of modeling groups around the world in climate simulations of the twentieth and twenty-first centuries prepared for the IPCC Fourth Assessment Report. They are publicly available (see http://www-loa.univ-lille1.fr/ $\sim$ boucher/sres).

[34] Acknowledgments. The authors would like to pay tribute to Gérard Mégie, who accompanied them during their respective careers. Computer time for this study was provided by the "Institut du Développement et des Ressources en Informatique Scientifique" (IDRIS) of the CNRS under projects 031167 and 041167. Matthias Beekman is acknowledged for his helpful advices.

\section{References}

Anderson, T. L., R. J. Charlson, S. E. Schwartz, R. Knutti, O. Boucher, H. Rodhe, and J. Heintzenberg (2003), Climate forcing by aerosols - A hazy picture, Science, 300, 1103-1104.

Boucher, O., and M. Pham (2002), History of sulfate aerosol radiative forcings, Geophys. Res. Lett., 29(9), 1308, doi:10.1029/2001GL014048. Boucher, O., M. Pham, and C. Venkataraman (2002), Simulation of the atmospheric sulfur cycle in the Laboratoire de Météorologie Dynamique General Circulation Model: Model description, model evaluation, and global and European budgets, Note Sci. de l'IPSL 23, Inst. PierreSimon Laplace, Paris. (Available from http://www.ipsl.jussieu.fr/poles/ Modelisation/NotesSciences.htm)

Boucher, O., et al. (2003), DMS atmospheric concentrations and sulphate aerosol indirect radiative forcing: A sensitivity study to the DMS source representation and oxidation, Atmos. Chem. Phys., 3, 49-65.

Driscoll, C. T., G. B. Lawrence, A. J. Bulger, T. J. Butler, C. S. Cronan, C. Eagar, K. F. Lambert, G. E. Likens, J. L. Stoddard, and K. C. Weathers (2001), Acidic deposition in the Northeastern United States: Sources and inputs, ecosystem effects, and management strategies, BioScience, 51, 180-198.

Economic Commission for Europe (ECE) (2002), Executive Body for the Convention on Long-Range Transboundary Air Pollution, ECE/EB.AIR/ 75, 16 Jan. (Available from http://www.unece.org/env)

Environmental Protection Agency (EPA) (1999), Progress report on the EPA Acid Rain Program, EPA430-R-99-011, Nov. (Available from http://www.epa.gov/acidrain)

Feichter, J., E. Roeckner, U. Lohmann, and B. Liepert (2004), Nonlinear aspects of the climate response to greenhouse gas and aerosol forcing, J. Clim., 17, 2384-2398.

Hansen, J. (2004), Defusing the global warming time bomb, Sci. Am., 290, $68-77$.

Hauglustaine, D. A., F. Hourdin, L. Jourdain, M.-A. Filiberti, S. Walters, J.-F. Lamarque, and E. A. Holland (2004), Interactive chemistry in the Laboratoire de Météorologie Dynamique general circulation model: Description and background tropospheric chemistry evaluation, J. Geophys. Res., 109, D04314, doi:10.1029/2003JD003957.

Hettelingh, J.-P., R. J. Downing, and P. A. M. de Smet (Eds.) (1995), Calculation and mapping of critical loads in Europe, RIVM Rep. 259101004, Coord. Cent. for Eff., Bilthoven, Netherlands.

Johns, T. C., et al. (2003), Anthropogenic climate change for 1860 to 2100 simulated with the HadCM3 model under updated emissions scenarios, Clim. Dyn., 20, 583-612, doi:10.1007/s00382-00260296-y.

Lefohn, A. S., J. D. Husar, and R. B. Husar (1999), Estimating historical anthropogenic global sulfur emission patterns for the period 1850-1990, Atmos. Environ., 33, 3345-3444.

Myhre, G., A. Myhre, and F. Stordal (2001), Historical evolution of radiative forcing of climate, Atmos. Environ., 35, 2361-2373.

Nakićenović, N., et al. (2000), Emissions Scenarios, A Special Report of Working Group III of the Intergovernmental Panel on Climate Change, 599 pp., Cambridge Univ. Press, New York. 
Nightingale, P. D., G. Malin, C. S. Law, A. J. Watson, P. S. Liss, M. I. Liddicoat, J. Boutin, and R. C. Upstill-Goddard (2000), In situ evaluation of air-sea exchange parameterizations using novel conservative and volatile tracers, Global Biogeochem. Cycles, 14, 373-387.

Nilsson, J., and P. Greenfelt (Eds.) (1988), Critical levels for sulphur and nitrogen, 418 pp., Nordic Counc. of Minist., Copenhagen, Denmark.

Novakov, T., V. Ramanathan, J. E. Hansen, T. W. Kirchstetter, M. Sato, J. E. Sinton, and J. A. Sathaye (2003), Large historical changes of fossil-fuel black carbon aerosols, Geophys. Res. Lett., 30(6), 1324, doi:10.1029/ 2002GL016345.

Örn, G., U. Hansson, and H. Rodhe (1996), Historical worldwide emissions of anthropogenic sulfur, $1860-1985,5$ pp. +15 figures, Rep. CM-91, Dep. of Meteorol., Stockholm Univ., Stockholm.

Penner, J., et al. (2001), Aerosols, their direct and indirect effects, in Climate Change 2001, The Scientific Basis, Contribution of Working Group I to the Third Assessment Report of the Intergovernmental Panel on Climate Change, edited by J. T. Houghton et al., pp. 289348, Cambridge Univ. Press, New York.

Ramaswamy, V., O. Boucher, J. Haigh, D. Hauglustaine, J. Haywood, G. Myhre, T. Nakajima, G. Y. Shi, and S. Solomon (2001), Radiative forcing of climate change, in Climate Change 2001, The Scientific Basis, Contribution of Working Group I to the Third Assessment Report of the International Panel on Climate Change, edited by J. T. Houghton et al., pp. 349-416, Cambridge Univ. Press, New York.
Rodhe, H., F. Dentener, and M. Schulz (2002), The global distribution of acidifying wet deposition, Environ. Sci. Technol., 36, 4382-4388.

Shah, J., et al. (2000), Integrated analysis for acid rain in Asia: Policy implications and results of RAINS-ASIA models, Ann. Rev. Energy Environ., 25, 339-375.

Twomey, S. (1974), Pollution and the planetary albedo, Atmos. Environ., 8, $1251-1256$.

van Aardenne, J. A., F. J. Dentener, J. G. J. Olivier, C. G. M. Klein Goldewijk, and J. Lelieveld (2001), A $1^{\circ} \times 1^{\circ}$ resolution data set of historical anthropogenic trace gas emissions for the period 1890-1990, Global Biogeochem. Cycles, 15, 909-928.

O. Boucher, Hadley Centre for Climate Prediction and Research, Met Office, Exeter EX1 3PB, UK

D. Hauglustaine, Laboratoire des Sciences du Climat et de l'Environnement, Institut Pierre-Simon Laplace, Orme des Merisiers, Bâtiment 709, 91191 Gif sur Yvette Cedex, France. (hauglustaine@cea.fr)

M. Pham, Service d'Aéronomie, Boîte 102, Institut Pierre-Simon Laplace, Université Pierre et Marie Curie, 4 Place Jussieu, 75230 Paris Cedex 05, France. (mai.pham@aero.jussieu.fr) 